\title{
Correction to: Autism, autistic traits and creativity: a systematic review and meta-analysis
}

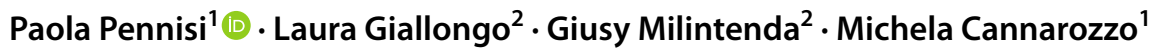

Published online: 30 August 2021

๑) Marta Olivetti Belardinelli and Springer-Verlag GmbH Germany, part of Springer Nature 2021

\section{Correction to: Cognitive Processing (2021) 22:1-36 https://doi.org/10.1007/s10339-020-00992-6}

In the original publication of the article, the first and last names of the authors are interchanged and published incorrectly. The correct author names are given below: Paola Pennisi, Laura Giallongo, Giusy Milintenda, Michela Cannarozzo.

The original article has been corrected.

Publisher's Note Springer Nature remains neutral with regard to jurisdictional claims in published maps and institutional affiliations.

The original article can be found online at https://doi.org/10.1007/ s10339-020-00992-6.

Paola Pennisi

ppennisi@unime.it

1 Department of Adult and Childhood, Human Pathology "Gaetano Barresi"; Hospital G. Martino, University of Messina, Via Consolare Valeria snc, 98125 Messina, Italy

2 Department of Cognitive Science, Education and Cultural Studies, University of Messina, Via Concezione 6/8, 98121 Messina, IT, Italy 